\title{
Q-switched erbium-doped fibre laser using graphene-based saturable absorber obtained by mechanical exfoliation
}

\author{
${ }^{1}$ Saleh Z. S., ${ }^{1}$ Anyi C. L., ${ }^{2}$ Rahman A. A., ${ }^{1}$ Ali N. M., ${ }^{3}$ Harun S. W., \\ ${ }^{2}$ Manaf M. and ${ }^{1}$ Arof $\mathrm{H}$. \\ ${ }^{1}$ Department of Electrical Engineering, Faculty of Engineering, University of \\ Malaya, 50603 Kuala Lumpur, Malaysia \\ ${ }^{2}$ Faculty of Computer \& Mathematical Sciences, Universiti Teknologi MARA, \\ 40450 Shah Alam, Selangor Darul Ehsan, Malaysia \\ ${ }^{3}$ Photonic Research Centre, University of Malaya, 50603 Kuala Lumpur, Malaysia
}

Received: 24.09 .2013

\begin{abstract}
A stable passively Q-switched erbium-doped fibre laser (EDFL) operating at $1536.5 \mathrm{~nm}$ is developed, using a $1 \mathrm{~m}$ long erbium-doped fibre as a gain medium and a simple graphene-based saturable absorber (SA). Using mechanical exfoliation, a single layer of graphene is obtained and deposited on the end facet of an optical fibre ferrule, which is then connected to another ferrule to form the SA. The SA is integrated into an EDFL cavity to achieve a stable pulse train at the threshold pump power of $42.3 \mathrm{~mW}$. When the pump power increases from 42.3 to $63.5 \mathrm{~mW}$, the pulse train repetition rate increases from 10.3 to $32.4 \mathrm{kHz}$, while the pulse width varies from 10.7 to $31.0 \mu$ s. The highest energy, $166.2 \mathrm{~nJ}$, is achieved at the pump power of $42.3 \mathrm{~mW}$.
\end{abstract}

Keywords: erbium-doped fibre laser, Q-switching, graphene saturable absorber, mechanical exfoliation

PACS: $42.55 . \mathrm{Wd}, 42.60 . \mathrm{Gd}$

UDC: $535.574: 621.375 .82+537.874 .37$

\section{Introduction}

Lasers operating in continuous-wave $(\mathrm{CW})$ or quasi-CW regimes generate a restricted output optical power, which is limited by a maximum available pump power. If the energy is concentrated in a single short optical pulse, or in a series of periodic optical pulses, higher peak powers can be achieved. Q-switching is a known technique that enables generating short optical pulses by suddenly switching cavity losses. Like the CW fibre lasers, high-peak-power Q-switched fibre lasers have many useful applications, such as range finding, remote sensing, industrial processing, and medicine [1-3]. Active Q-switching is typically achieved by inserting acousto-optic or electrooptic modulators into the cavity. In contrast, passive Q-switching is based on saturable absorbers (SAs) like semiconductor saturable-absorber mirrors (SESAMs) $[4,5]$ or carbon nanotubes (CNTs) [6, 7], with no external Q-switching electronics. The passive Q-switching is convenient since it greatly simplifies a design of the cavity. However, fabrication of SESAMs is very cumbersome and costly. The CNT SAs are simpler to fabricate and more cost effective. Nonetheless, when operating at a particular wavelength, the CNT SAs require band-gap tuning by controlling their diameters and chirality. Moreover, the surface tension of the CNT SAs is too large, so that the devices suffer from a low damage threshold [8].

Recently, much attention has been given to graphene as a novel nanomaterial for broadband functional SAs [9]. Graphene represents a 2D crystal in which carbon atoms are arranged in a 
honeycomb lattice. The first isolated graphene nanosheets have been produced by mechanical exfoliation from bulk graphite in 2004 [10]. Graphene has outstanding linear and nonlinear optical properties, such as a low threshold level of saturable absorption $\left(\sim 0.7 \mathrm{MW} \times \mathrm{cm}^{-2}\right)$, ultrafast recovery time (200 fs) and an ultra-broad wavelength region of saturable absorption, which covers visible and mid-IR ranges. Compared with the CNTs, graphene has a higher damage threshold due to its 2D structure [11]. Until recently, the most of the works that involved graphene have been focused on mode-locked fibre lasers [11-13]. The reports on the Q-switched fibre lasers based upon graphene have been concerned mainly with graphene films obtained using chemical vapour deposition $[14,15]$.

In this work we demonstrate successful operation at $1536.5 \mathrm{~nm}$ of a Q-switched erbiumdoped fibre laser (EDFL). It employs a simple and cheap graphene-based SA. The graphene layer integrated into the SA is fabricated by a mechanical exfoliation technique. The SA is incorporated in the EDFL to achieve a stable pulse train with the threshold pump power of $42.3 \mathrm{~mW}$. The laser uses a one-metre long erbium-doped fibre as a gain medium and produces a stable pulse train with the highest energy of $166.2 \mathrm{~nJ}$.

\section{Fabrication of SA and experimental setup}

The first step in setting up our Q-switched EDFL is fabricating a graphene SA which plays a key role as a passive Q-switcher. The graphene SA was constructed by depositing single-layer graphene on the end facet of an optical fibre ferrule, using a mechanical exfoliation technique. Commercially available highly ordered pyrolytic graphite was used as a working material. First, flakes of that material were pasted onto a strip of scotch tape and pressed and peeled off repeatedly, in order to optimize the graphene thickness. The resulting graphene strip was then pressed against the end facet of the optical fibre ferrule. The scotch tape was slowly peeled off so that the graphene layer remained on the end facet of the ferrule. Finally, the latter was connected to another fibre pigtail via a connector (FC/PC), to form a simple SA device for the fibre laser.

Fig. 1 shows a scheme of our Q-switched EDFL. It involves a $980 \mathrm{~nm}$ laser diode as a pump source, a wavelength division multiplexer, an optical isolator, a 95/5 dB output coupler, a onemetre long erbium-doped fibre as a gain medium and the graphene SA prepared as said above. The erbium-doped fibre had the core and cladding with the diameters equal respectively to 4 and

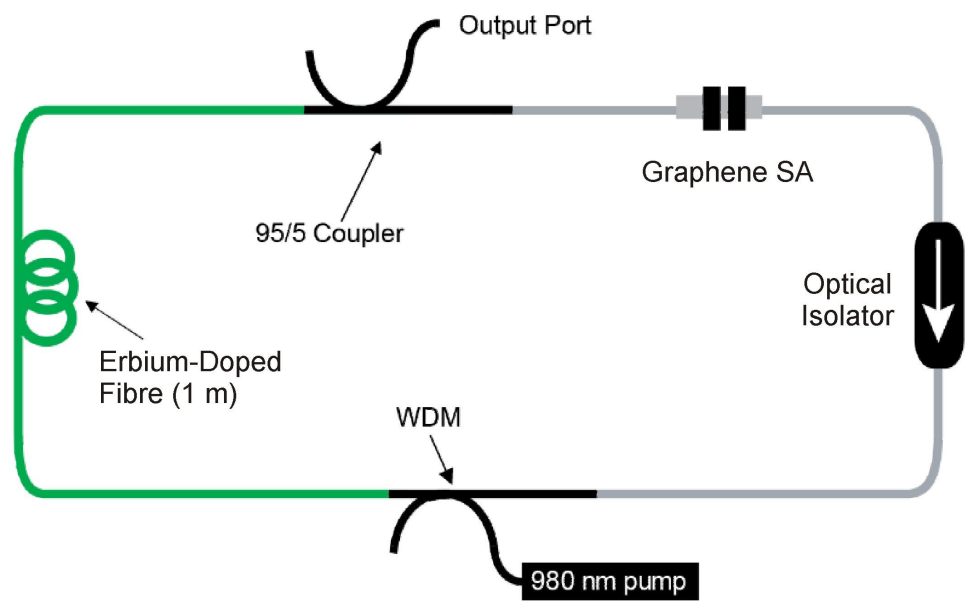

Fig. 1. Schematic configuration of our Q-switched EDFL.
$125 \mu \mathrm{m}$, the numerical aperture 0.16 , and the erbium-ion absorption $23 \mathrm{~dB} / \mathrm{m}$ at $980 \mathrm{~nm}$. It was pumped by the laser diode via the wavelength division multiplexer. The isolator was inserted in the laser cavity to ensure unidirectional propagation of the oscillating laser light. The output of the laser was taken out of the cavity through the 95/5 coupler which 
kept 95 per cent of light to oscillate in the ring cavity. An optical spectrum analyzer with the spectral resolution of $0.02 \mathrm{~nm}$ served for inspecting the EDFL light. Finally, an oscilloscope was used to observe the output pulse train detected with a $460 \mathrm{kHz}$ bandwidth photodetector (Thor lab, PDA50B-EC).

\section{Results and discussion}

A stable Q-switching self-starts whenever the pump power is adjusted to be higher than the threshold value $42.3 \mathrm{~mW}$. Fig. 2 illustrates the attenuated output spectrum of the Q-switched EDFL for the case when the pump power is fixed at $48.3 \mathrm{~mW}$. The laser works at the wavelength of $1536.5 \mathrm{~nm}$, the average output power being $2.1 \mathrm{~mW}$. One can see that the EDFL operates in the $\mathrm{CW}$ mode if no graphene SA is inserted into the cavity. The inset of Fig. 2 shows the Raman spectrum for the graphene-deposited fibre ferrule, which has been detected using a CCD camera and a laser excitation at $532 \mathrm{~nm}(2.33 \mathrm{eV})$. Two prominent peaks are observed in the spectrum. One of them is located approximately at $1580 \mathrm{~cm}^{-1}$ and is generally known as a so-called $G$ peak. The other one which is termed as a $2-D$ peak is centred at $\sim 2700 \mathrm{~cm}^{-1}$. The intensity ratio for the peaks $G$ and $2-D$ is equal to about 0.48 , thus indicating that the single-layer graphene is successfully transferred on the fibre ferrule.

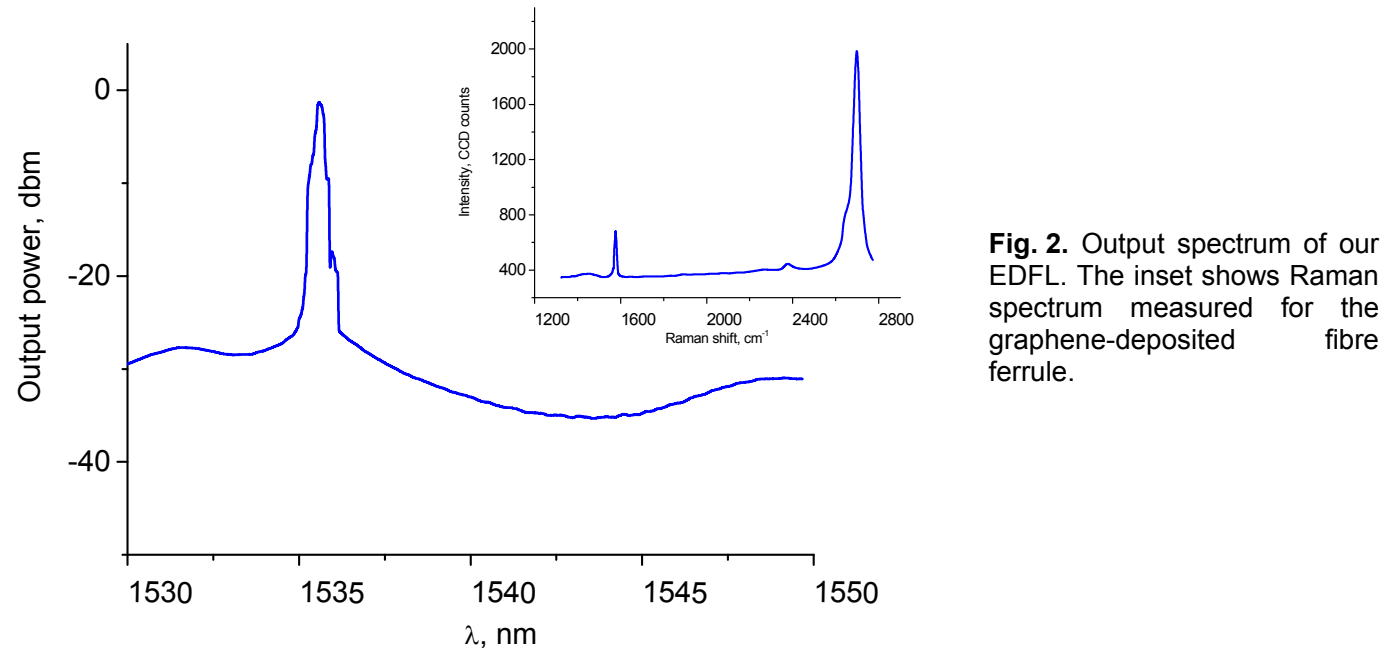

Fig. 3a displays an oscilloscope trace of the Q-switched pulse train at the pump power of $51.4 \mathrm{~mW}$. There is no distinct amplitude modulation in each of the Q-switched envelops. This means that the effect of self-mode-locking on the Q-switching remains weak. At the pump power mentioned above, the laser produces a stable Q-switched pulse train with the repetition rate of $20.6 \mathrm{kHz}$. Fig. 3b shows a typical oscilloscope trace of the pulse envelop. The full width at half maximum, taken as a pulse width, amounts to $20.2 \mu \mathrm{s}$.

Fig. 4 shows dependences of the repetition rate and the pulse width on the pump power. The repetition rate of the graphene-based Q-switched EDFL monotonically increases with increasing pump power level, the relationship being nearly linear. When the pump power is tuned from 42.3 to $63.5 \mathrm{~mW}$, the repetition rate of pulses in the train changes from 10.3 to $32.4 \mathrm{kHz}$. Then the pulse width decreases from 31.0 to $10.7 \mu \mathrm{s}$. The pulse width is expected to drop further on for higher pump powers. This trend is limited by the damage threshold of the graphene SA. Fig. 5 shows the average output power and the pulse energy of the Q-switched EDFL as functions of the pump power. The output power increases with increasing pump power; the pulse energy decreases 
from 166.2 to $89.9 \mathrm{~nJ}$ in the pump power region of $42.3-63.5 \mathrm{~mW}$. At the maximum pump power, a stable Q-switching occurs, with the highest average power $2.9 \mathrm{~mW}$ and the corresponding pulse
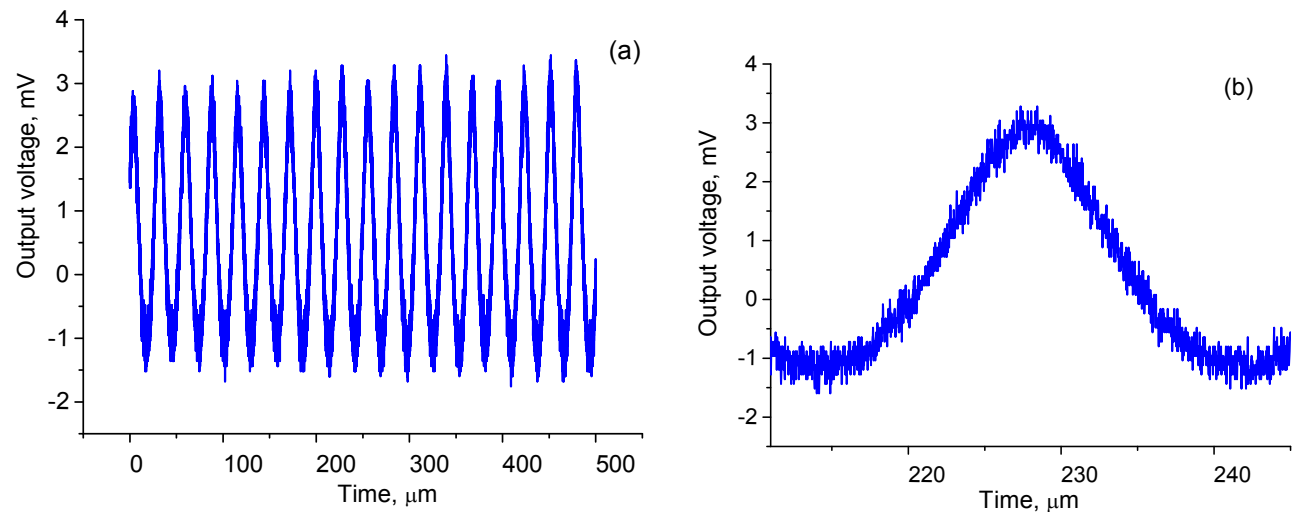

Fig. 3. (a) Oscilloscope trace of the pulse train of EDFL with the graphene-based SA (the pump power is equal to $51.4 \mathrm{~mW}$ and the repetition rate to $20.6 \mathrm{kHz}$ ); (b) one of the pulses on a larger scale.

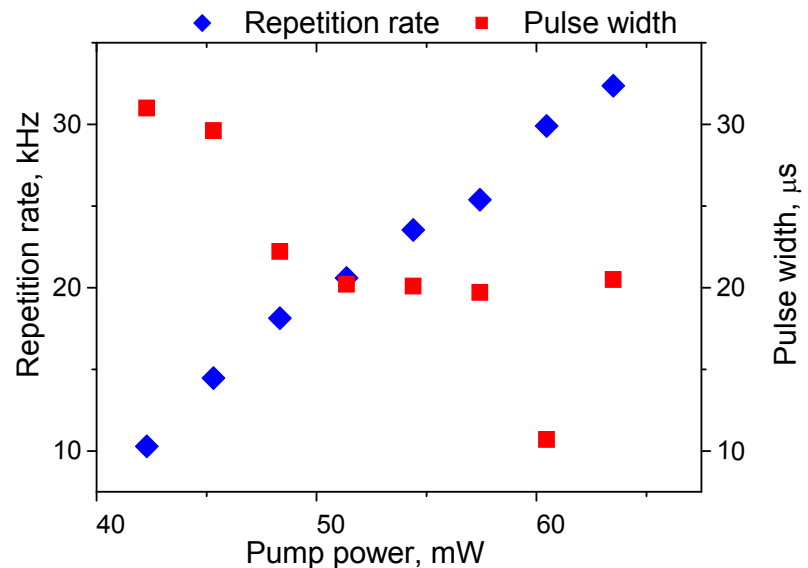

Fig. 4. Repetition rate and pulse width as functions of the pump power.

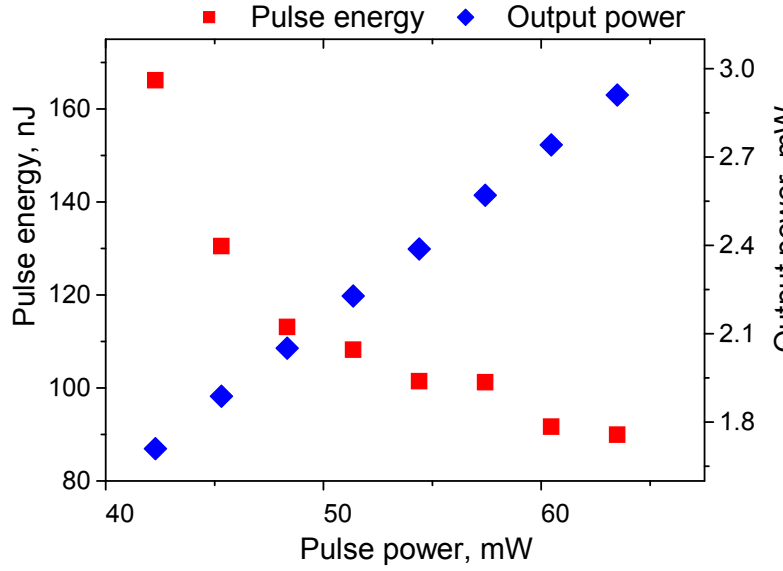

Fig. 5. Output power and pulse energy versus the pump power.

energy as high as $89.9 \mathrm{~nJ}$. The pulse energy could be further improved by reducing the insertion losses of the SA and optimizing the laser cavity. Hence, it seems that, under the conditions of careful manufacturing in the laser systems, the graphene has a large potential for superior Q-switching and saturable absorption, when compared with the conventional light-absorbing components. Fabrication of the corresponding SAs is also simple, thus lowering the cost of the 
lasers. As a consequence, the simple and low-cost lasers of this type can find numerous applications in metrology, environmental sensing and biomedical diagnostics.

\section{Conclusion}

We have demonstrated Q-switching in an EDFL based on a single-layer graphene-based SA. The graphene layer has been obtained from the highly ordered pyrolytic graphite, using the technique of mechanical exfoliation. The SA is constructed by pasting a single-layer graphene on the end facet of an optical fibre ferrule. The laser operates at $1536.5 \mathrm{~nm}$ and self-starts at the pump threshold of $42.3 \mathrm{~mW}$ to produce Q-switched pulses. When the pump power increases, the repetition rate changes from 10.3 to $32.4 \mathrm{kHz}$ and the pulse width from 31.0 to $10.7 \mu$ s. The highest energy, $166.2 \mathrm{~nJ}$, has been achieved at the pump power of $42.3 \mathrm{~mW}$. Graphene-based Qswitched fibre lasers with still higher performance can be manufactured after optimizing both the graphene SA and the laser cavity.

\section{Acknowledgment}

This work was supported by the Ministry of Higher Education under the Exploratory Research Grant Scheme, ERGS (Grant No: ER012-2012A).

\section{References}

1. Kobtsev S M, Kukarin S V and Fedotov Y S, 2008. High-energy Q-switched fiber laser based on the side-pumped active fiber. Laser Phys. 18: 1230-1233.

2. Wang $\mathrm{Y}$ and $\mathrm{Xu} \mathrm{C}-\mathrm{Q}, 2007$. Actively Q-switched fiber lasers: Switching dynamics and nonlinear processes. Progr. Quant. Electron. 31: 131-216.

3. Lin $\mathrm{J}-\mathrm{H}$, Lin $\mathrm{K}-\mathrm{H}$, Hsu $\mathrm{C}-\mathrm{C}$, Yang $\mathrm{W}$ H and Hsieh $\mathrm{W}-\mathrm{F}, 2007$. Supercontinuum generation in a microstructured optical fiber by picosecond self Q-switched mode-locked $\mathrm{Nd}: \mathrm{GdVO}_{4}$ laser. Laser Phys. Lett. 4: 413-415.

4. Yang W, Hou J, Zhang B, Song R and Liu Z, 2012. Semiconductor saturable absorber mirror passively Q-switched fiber laser near $2 \mu \mathrm{m}$. Appl. Opt. 51: 5664-5667.

5. Wang H-Y, Xu W-C, Luo A-P, Dong J-L, Cao W-J and Wang L-Y, 2012. Controllable dissipative soliton and Q-switched pulse emission in a normal dispersion fiber laser using SESAM and cavity loss tuning mechanism. Opt. Commun. 285: 1905-1907.

6. Harun S W, Ismail M A, Ahmad F, Ismail M F, Nor R M, Zulkepely N R and Ahmad H, 2012. A Q-switched erbium-doped fiber laser with a carbon nanotube based saturable absorber. Chinese Phys. Lett. 29: 114202.

7. Ismail M A, Harun S W, Zulkepely N R, Nor R M, Ahmad F and Ahmad H, 2012. Nanosecond soliton pulse generation by mode-locked erbium-doped fiber laser using singlewalled carbon-nanotube-based saturable absorber. Appl. Opt. 51: 8621-8624.

8. Hasan T, Sun Z, Wang F, Bonaccorso F, Tan P H, Rozhin A G and Ferrari A C, 2009. Nanotube-polymer composites for ultrafast photonics. Adv. Mater. 21: 3874-3899.

9. Bonaccorso F, Sun Z, Hasan T and Ferrari A C, 2010. Graphene photonics and optoelectronics. Nature Photonics. 4: 611-622.

10. Novoselov K S, Geim A K, Morozov S V, Jiang D, Zhang Y, Dubonos S V, Grigorieva I V and Firsov A A, 2004. Electric field effect in atomically thin carbon films. Science. 306: 666669.

11. Zhang H, Tang D Y, Zhao L M, Bao Q L and Loh K P, 2009. Large energy mode locking of an erbium-doped fiber laser with atomic layer graphene. Opt. Express. 17: 17630. 
12. Popa D, Sun Z, Torrisi F, Hasan T, Wang F and Ferrari A C, 2010. Sub 200 fs pulse generation from a graphene mode-locked fiber laser. Appl. Phys. Lett. 97: 203106.

13. Sun Z, Hasan T, Torrisi F, Popa D, Privitera G, Wang F, Bonaccorso F, Basko D M and Ferrari A C, 2010. Graphene mode-locked ultrafast laser. ACS Nano. 4: 803-810.

14. Jiang T M, Ma H F, Ren Z Y, Chen X M, Long J Y, Qi M, Shen D Y, Wang Y S and Bai J T, 2013. A graphene Q-switched nanosecond Tm-doped fiber laser at $2 \mu \mathrm{m}$. Laser Phys. Lett. 10: 055103.

15. Zhang L Q, Zhuo Z, Wang J X and Wang Y Z, 2012. Passively Q-switched fiber laser based on graphene saturable absorber. Laser Phys. 22: 433-436.

16. Huang N M, Lim H N, Chia C H, Yarmo A and Muhamad M R, 2011. Simple roomtemperature preparation of high-yield large-area graphene oxide. Int. J. Nanomedicine. 6: 3443-3448.

17. Ferrari A C, Meyer J C, Scardaci V, Casiraghi C, Lazzeri M, Mauri F, Piscanec S, Jiang D, Novoselov K S, Roth S and Geim A K, 2006. Raman spectrum of graphene and graphene layers. Phys. Rev. Lett. 97: 187401.

18. Chen S, Brown L, Levendorf M, Cai W, Ju S-Y, Edgeworth J, Li X, Magnuson C W, Velamakanni A, Piner R D, Kang J, Park J and Ruoff R S, 2011. Oxidation resistance of graphene-coated $\mathrm{Cu}$ and $\mathrm{Cu} / \mathrm{Ni}$ alloy. ACS Nano. 5: 1321-1327.

Saleh Z. S., Anyi C. L., Rahman A. A., Ali N. M., Harun S. W., Manaf M. and Arof H. 2014. Q-switched erbium-doped fibre laser using graphene-based saturable absorber obtained by mechanical exfoliation. Ukr.J.Phys.Opt. 15: $24-29$.

Анотація. Продемонстровано стабільне функціонування волоконного лазера на основі легованого ербію та пасивної модуляції добротності. Лазер складається з легованого ербієм волокна завдовжки $1 \mathrm{M}$, ш⿻ слугує підсилюючим середовищем, $i$ простого та дешевого графенового поглинача з насиченням. Лазер випромінює на довжині хвилі 1536,5 нм. Моношар графену отримано механічним відшаруванням. Поглинач з насиченням формували, наносячи цей моношар на торецьь оптичної волоконної муфти, приєднаної до іншої муфти. Поглинач інтегрували в резонатор волоконного лазера для досягнення стабільного набору імпульсів при пороговій потужності нагнітання $42,3 \mathrm{mBm}$. $3 і$ зростанням потужності нагнітання від 42,3 до 63,5 мBт частота повторення імпульсів зростала від 10,3 до 32,4 кГи, а тривалість імпульса змінювалася від 10,7 до 31,0 мкс. Найвищу енергію 166,2 нДж було досягнуто за потужності нагнітання 42,3 мBm. 